\title{
Application of Real Time GIS, Remote Sensing and IC Tag for Realization of Geospatial Information Society
}

\author{
Shikada Masaaki*, Takeuchi Sayaka*, Shimano Sota** \\ and Moriya Mitoshi*** \\ Kanazawa Institute of Technology (KIT)* \\ KOKUSAI KOGYO CO., LTD.** \\ ASIA AIR SURVEY CO., LTD.*** \\ JAPAN
}

\section{Introduction}

Japan is now experiencing an aging society and every person should be safe and feel relieved. The Japanese Government executed a new law NSDI for a spatial information society on May 30, 2007. (NSDI: National Spatial Data Infrastructure) The society needs to obtain absolute position for realizing seamless positioning by ubiquitous network technology. However, the technology has not been established yet. An experiment was performed on whether Real-Time GIS (Figure 1), GPS, and the IC tag could obtain the absolute position.

The research is to confirm whether absolute positions can be obtained accurately by Real-Time Kinematic-GPS (RTK-GPS), Virtual Reference System-GPS (VRS-GPS), and Differential-GPS (D-GPS). In addition, Integrated Circuit Tag (IC tag) was used where GPS signals could not be received to obtain information on the absolute position. The IC tag is used in distribution systems, but the method for using geoinfomatics has not been established yet. The experiment was conducted to verify the reading rate of IC tag on different types and conditions. The kinds of the IC tag are passive and active types. For example, the IC tag has many advantages of transmitting and receiving the information, and obtaining the absolute position without any contact. A passive and active IC tags made of different materials were experimented to verify the reading rate at the outside and inside of a laboratory. As a result, passive type IC tag become accurate, however, the active type is in a stage of growth because it is no clear method for using by various affect. Therefore it is necessary to do additional experiment of indoor positioning.

Second big purpose of the research is to establish Universal Map (UM). The basis of UM is a surveying and it consists of geoinformatics which is the latest survey technology. Anyone can use UM regardless of the physically challenged, healthy person, age, man and woman. Figure 2 shows the essential and minimum requirements of UM and the concept of UM.UM means the newest map which can display the latest road condition and other information on 
a mobile PC. This map includes the recent information by which all users can understand the condition of absolute position anytime, anywhere. Additionally, measures to utilize spatial information become extremely important and the society might need UM with a lot of advantages in the future. Our research suggested that we have to establish a method for acquiring seamless positioning information in the advanced spatial information society by using UM.

\section{Pedestrian Space}

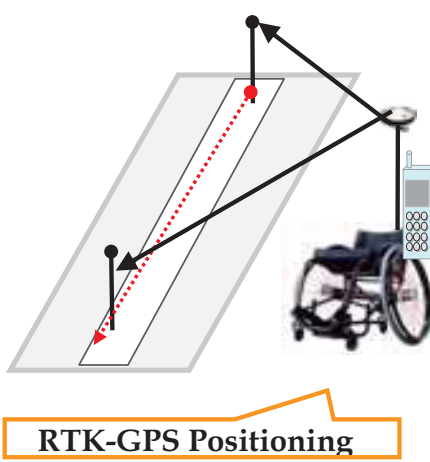

GIS Server

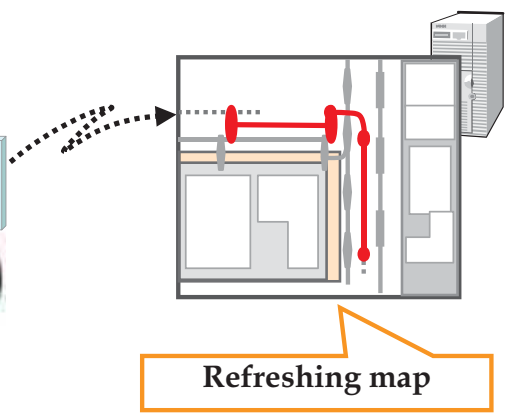

Fig. 1. Concept of REAL TIME GIS

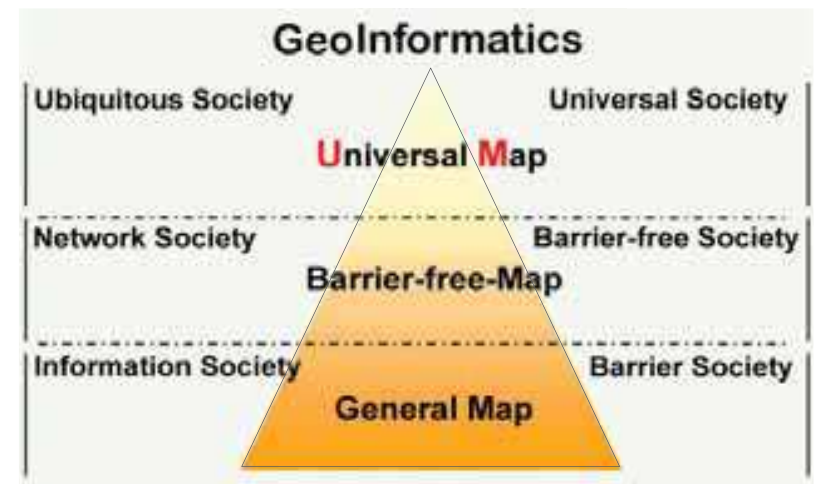

Basis of Survey

Fig. 2. Concept of Universal Map

\section{Background of Study}

"The map should be fresh" is a big concept of our laboratory. One of the backgrounds of study is to establish a method for updating a large-scale digital map for local government using a Real-Time GIS (Figure 1). The Real-Time GIS which was defined by our laboratory can be used to renew the new BM. The Real-Time GIS is a technique that updates the new BM instantly by the Real-Time Kinematic Global Positioning System (RTK-GPS), GIS, and mobile phones. 
Japan has been adopting a new standard for map geometry since April 1, 2002. Ellipsoid of a new geodetic system in Japan is almost equal to WGS- 84 of GPS but most of the Digital Map (DM) of local government is still Tokyo Datum of an old geodetic system. To correspond with two kinds of data which have different geodetic systems, it is necessary to transform coordinates.

On the other hand, much local government has been utilizing a large scale $(1 / 500$ or $1 / 1000)$ DM with GIS. Government promulgated the law of National Spatial Data Infrastructure (NSDI) to construct the advanced spatial information society May 2007. GIS will be able to efficiently help many workers who are managers and city planners in government and researchers. As an example, it is possible to improve the service to a citizen including elderly people and the physically challenged by sharing those data in local government. However, the maintenance and renewal of UM database need much labor and time and updating a map has not been established yet and, there are only a few successful examples. This is a specific problem of a large scale map to achieve the spatial information society now.

In the master's thesis of Ms. Naoko Matsuda who graduated 2003 from Kanazawa Institute of Technology (KIT), these problems were solved by using Real Time GIS and the achieved result is listed below.

(1) Position data of latitude and longitude had a high accuracy within $3 \mathrm{~cm}$.

(2) It is difficult to acquire high-accuracy data because geoids may influence the accuracy of height.

(3) Tracks were not displayed well though she tried to display tracks which moved by using a RTK-GPS in GIS because canopies interrupt wavelengths from satellites.

As a result, at that stage, it was very difficult to solve problems by using a GPS only. Interruption of signals in course includes very important problems. If anyone is able to receive the positioning data ubiquitously, people will obtain safe, relieved, and comfortable service.

The purpose of this study at the first stage was to establish a method for updating a large scale map for local government, and to propose UM by using RS, GPS, and GIS. On the second stage, we adopted new concepts of collaboration of geoinformatics technologies. On the present stage, the important purpose of study is how to acquire the accurate positioning information without interrupting satellites information.

\section{Experiment by GPS Positioning}

An experiment was performed inside the KIT campus at Kanazawa district in central Japan by using a D-GPS and a VRS-GPS. The purpose of the experiment is to acquire positional data accurately and to understand the feature of places where accuracy is poor. Accuracy of positioning D-GPS and VRS-GPS was verified.

Figure 3 shows the experiment field and the route. Background of Figure 3 is Base Map of the Nonoichi town on a scale of 1/2500 (Accept: Nonoichi town office). ArcGIS 9.1 which is one of the general software of GIS was used to display the map and analyze the data. 


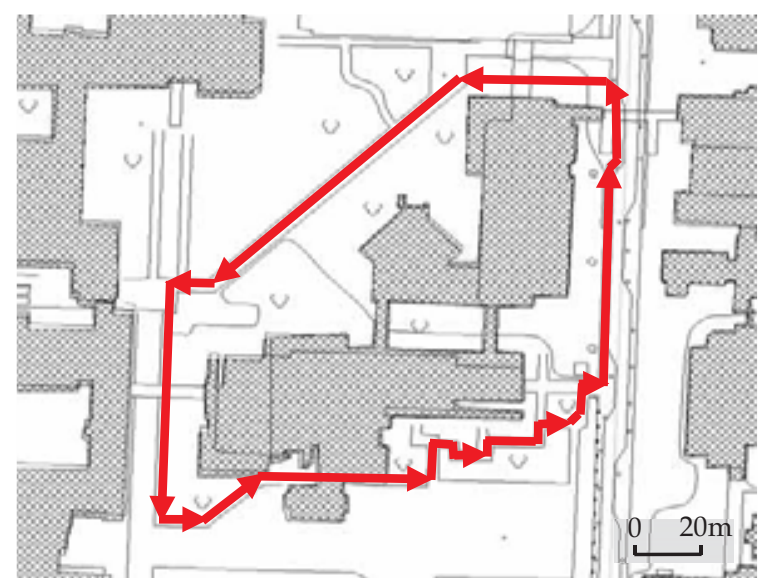

Fig. 3. Experiment field and route in KIT campus

\subsection{RTK-GPS Positioning}

In this paper, RTK-GPS means that a reference station and a rover station were required for real-time GPS positioning. The reference station was made just on a control point. This control point is a leveling point which has the absolute position because the accurate positioning data by using static positioning were needed. The specified low power radio broadcast is used on the communication from the reference station to the rover station for the RTK-GPS receiver.

The experiment was conducted by moving around by a wheelchair which is equipped with RTK-GPS at uniform speed inside KIT campus. Additionally, we have carried out the experiment by holding the RTK-GPS equipment with hands. In that condition, we could not obtain positioning data because a GPS antenna was swung on moving. This is the reason why a GPS was attached to the wheelchair or a hand truck for reducing an error. However, many errors happened in the most of fields by using a RTK-GPS. One of the reasons for causing errors was the buildings between the positioning points because the communication area of radio broadcasts was narrow in such a situation.

\subsection{VRS-GPS Positioning}

A second experiment was performed by using VRS-GPS that is a kind of RTK-GPS positioning. In VRS-GPS, the reference station needs not be set. A virtual reference station was made virtually around the positioning point. The distance of a virtual point to an actual point is about $3 \mathrm{~m}$ to $5 \mathrm{~m}$. A rover station received correction information from a mobile phone by using a wireless system. This system consists of GPS-based control stations. GSI made it about 1200 stations in Japan. In the wireless system, only one person is capable of positioning with a light baggage. 


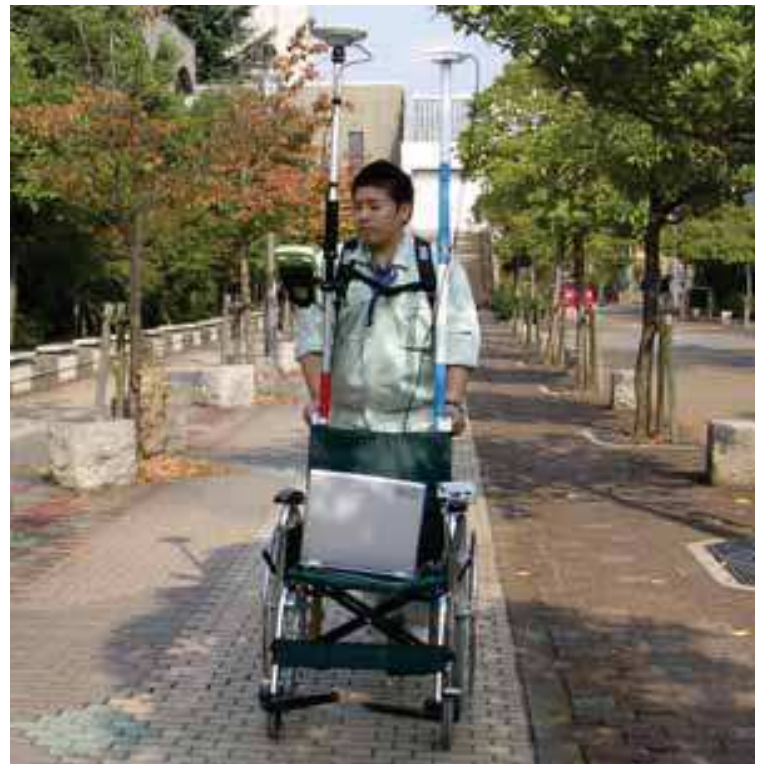

Fig. 4. Positioning of D-GPS and VRS-GPS

The method of measurement is similar to that of RTK-GPS. Therefore, VRS-GPS has more advantages. More specifically, it allows only one person to make real-time positioning, has a simple configuration, and has high accuracy.

\subsection{D-GPS Positioning}

D-GPS positioning is a method that sends the corrected value of a pseudo distance from each satellite, and calculates precision again in the rover station. Additionally, a rover station received correction data from a mobile phone by using GPS-based control station. Position accuracy is from $0.5 \mathrm{~m}$ to $2.0 \mathrm{~m}$. This system is similar to the technique of VRS-GPS and it only needs a rover station. Moreover, the positioning cost is cheaper than that VRS-GPS because of its simple system. The experiment performed by using a wheelchair with D-GPS and VRS-GPS simultaneously. The reason is to make the experimental environment almost the same and to acquire position data. Figure 4 shows the positioning of D-GPS and VRS-GPS by a wheelchair.

\section{Verification of Overlapping}

Positioning data of D-GPS and VRS-GPS were displayed on the DM (Base Map of the Nonoichi town on a scale of 1/2500) by using GIS software (Figure 5). Background of Figure 5 is an aerial photograph.

\subsection{Experiment Result}

As a result of experiments, GPS was able to receive high-accuracy data at almost all places. However, the data were not accurate at any places though the measured place had wide 
open sky. It seemed that other reasons affect a receiver. Data were intercepted at three spots, and a lot of measurement errors occurred there.

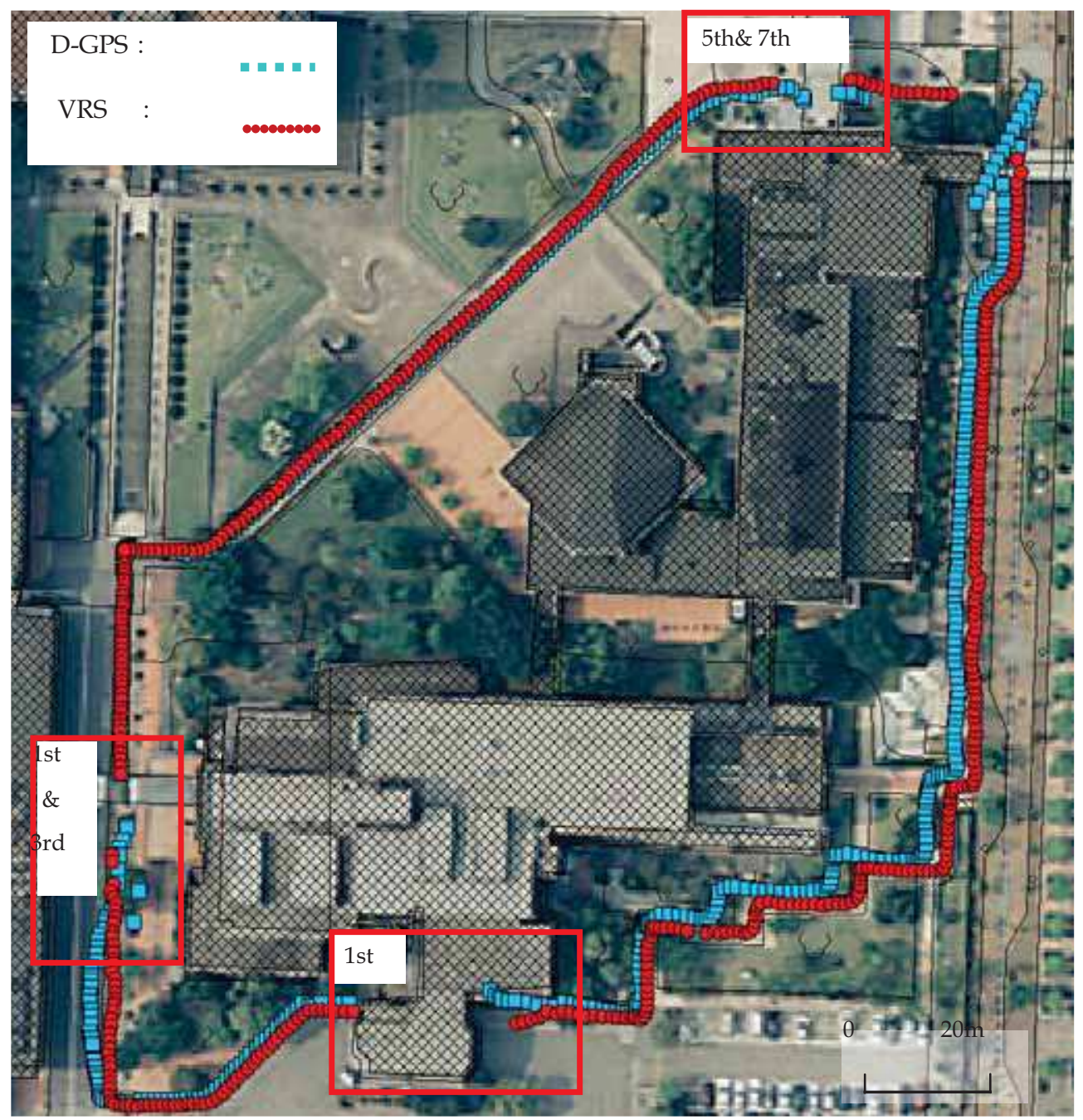

Fig. 5. Overlapping of experiment data

In the next stage, we confirmed how long a signal is received around a canopy by a D-GPS and a VRS-GPS. Figure 6 (a), (b) and (c) shows one of enlarged canopy areas in Figure 5.

Table 1 shows the length of interruption of raw data that were displayed on GIS. Table 2 shows the length of interruption of analytical data that include positional accuracy and error. For example, we considered dilution of precision (DOP), number of satellites, and standard deviation. 
Application of Real Time GIS,

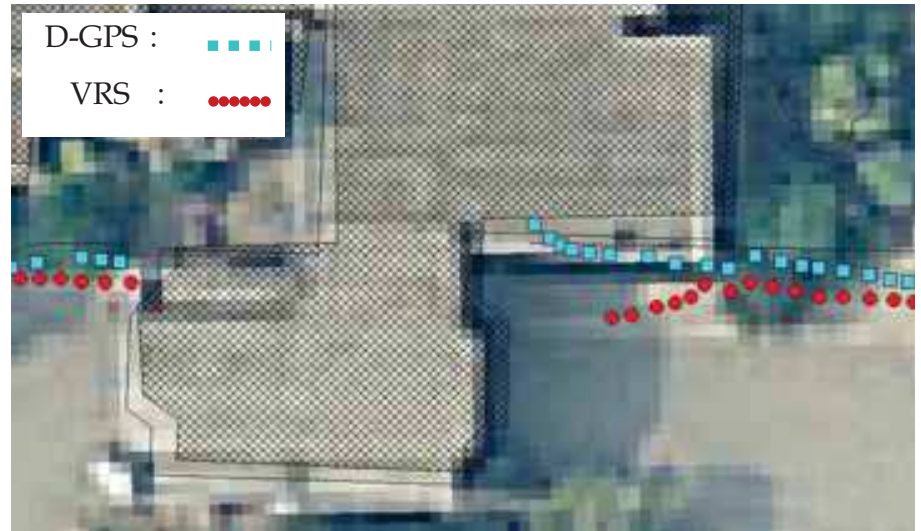

Fig. 6 .(a) Verification around each canopy (Front stoop of 1st building)

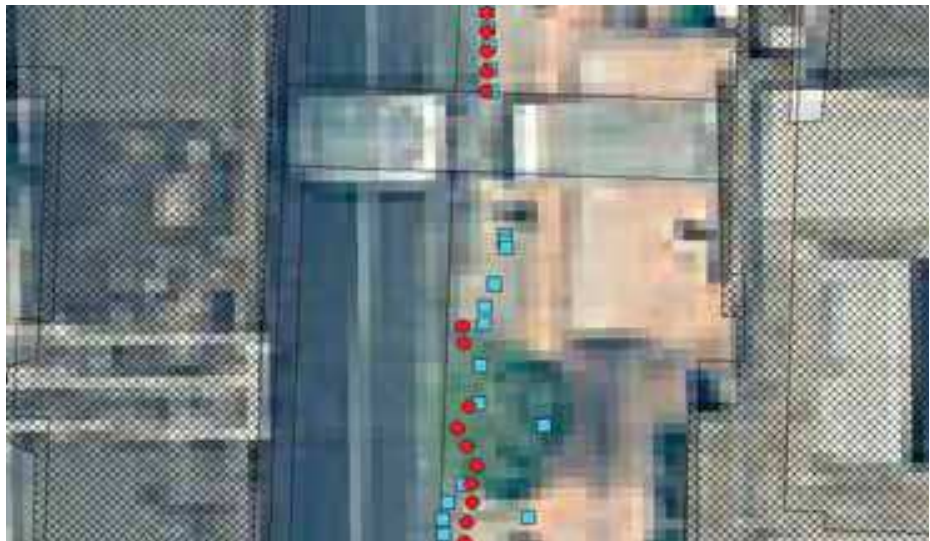

Fig. 6 .(b) Verification around each canopy (between 1st and 3rd building)

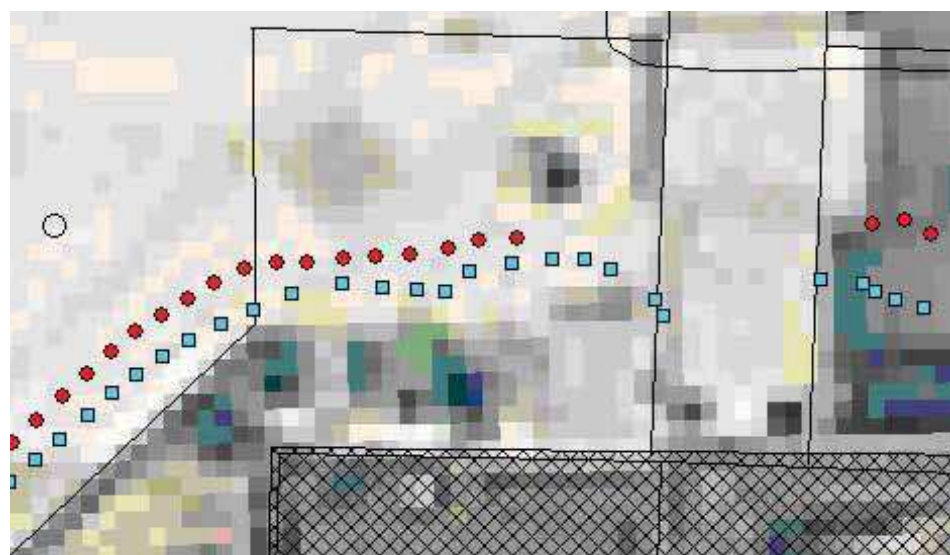

Fig. 6. (c) Verification around each canopy (Between 5th and 7th building) 


\begin{tabular}{|c|c|c|}
\hline \multirow{2}{*}{ Building No. } & \multicolumn{2}{|c|}{ Length of interrupted tracks } \\
\cline { 2 - 3 } & D-GPS(m) & VRS-GPS(m) \\
\hline 1st & 4.624 & 7.908 \\
\hline 1st and 3rd & 5.119 & 7.396 \\
\hline 5th and 7th & 2.374 & 5.419 \\
\hline
\end{tabular}

Table 1. Length of interruption in raw data

\begin{tabular}{|c|c|c|}
\hline \multirow{2}{*}{ Building No. } & \multicolumn{2}{|c|}{ Length of interrupted tracks } \\
\cline { 2 - 3 } & D-GPS(m) & VRS-GPS(m) \\
\hline 1st & 15.313 & 12.574 \\
\hline 1st and 3rd & null & 12.130 \\
\hline 5th and 7th & 12.952 & 5.419 \\
\hline
\end{tabular}

Table 2. Length of interruption in analytical data

\subsection{Consideration}

Important condition of GPS positioning is to receive 4 satellites or more at open sky. As a result, I acquired the absolute position accurately at open sky. However GPS receiver was not able to receive signals from GPS satellites at an area surrounded by canopies and buildings. Additionally, one could not obtain continuous GPS signals at districts overgrown with trees. In such a place, correction data received by a mobile phone might not give acceptable data. An area surrounded by canopies and buildings causes that cycle slip and multipath to badly influence the DOP and GPS signals. If GPS positioning is conducted near buildings, it is necessary to consider satellites situation and multi-path. Because those areas had poor signal conditions, remarkable differences were seen between D-GPS and VRS-GPS. Interrupted signals of the D-GPS were shorter than those of the VRS-GPS as shown in Table 1, but VRS-GPS showed higher accuracy than that of D-GPS as shown in Table 2. As for the reasons for difference, VRS-GPS have the problem of initialization and D-GPS of simple system don't have one. Therefore, it appears D-GPS had high continuousness and VRS-GPS had reliability of positioning accuracy.

In the next chapter, we will show how to obtain an absolute position and other information at a place where the GPS signal does not reach.

\section{Solution of Problems by IC Tag and Geoinformatics}

Pedestrian space will become safer and securer if people are able to receive absolute positions and other information by future spatial information technology. In this technology, we will adopt an Integrated Circuit tag (IC tag) to assist people including the physically challenged. Major advantages of IC tag are listed below.

The IC tag can

- Receive the data without contact.

- Memorize a lot of data and be very small size.

- Easily add information and update data.

- Have high durability is better than that of its paper type. 
If IC tag's powerful advantage is used fully, everyone will be able to receive the positioning data anytime and anywhere. For example, GPS positioning is used at open sky, and IC tags are used at closed sky, which are good ideas because one can continuously receive the signal from satellites and IC tags. In this system, the positioning information will be imagined ubiquitously (Figure 7).

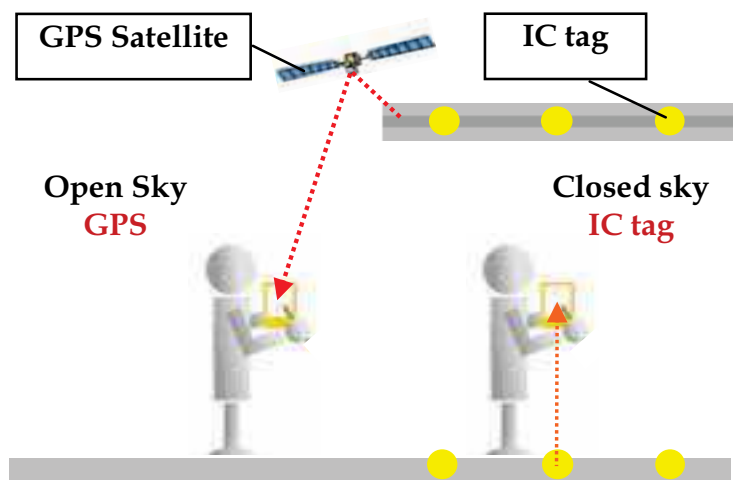

Fig. 7. Utilization of IC tag

\section{Experiment by IC Tags for Spatial Information Society}

Preliminary experiments were performed by using reader of middle-range and several IC tags which frequency band is $13.56 \mathrm{MHz}$. The purpose of experiments is to obtain basic data of IC tags for realization of seamless positioning. The experiment was conducted by using hand truck which attached the IC tag reader. IC tags were lineally set out and Unique Identifier (UID) of them was read by moving on the straight line (Figure 8). Additionally, the ratio of UID reading was indicated that how many pieces are able to read among 1000 tags. As a result of experiments, the maximum reading distance was about $40 \mathrm{~cm}$ though the specification of it is $50 \mathrm{~cm}$. Therefore, the height of IC tag's reader fixed from $15 \mathrm{~cm}$ to $40 \mathrm{~cm}$ in consideration for the condition of hand truck. After the experiments, we found that the error factor of IC tags and good measurement environment of reading rate.

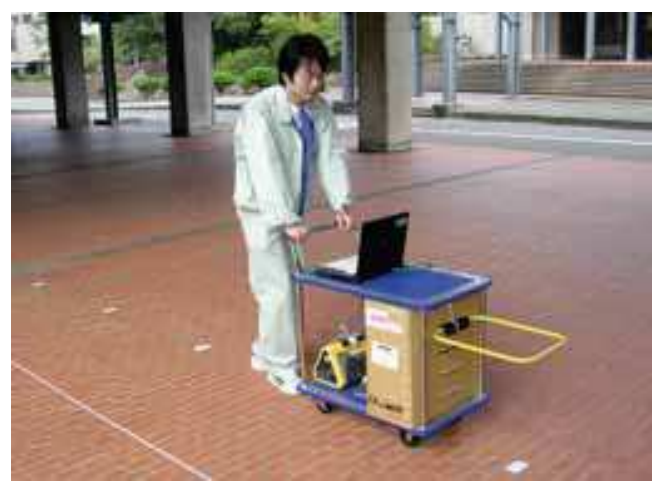

Fig. 8. Verification experiment of IC tag 
Several experiments were conducted to confirm influence of reading rate. Each condition for research and experimental overview are listed below.

(1)Material of the ground: It can easily influence that the metal, the water and other materials for to IC tag. First experiment was performed at any places such as cement concrete, asphalt concrete, earthenware tile and fireclay brick.

(2)Interval of IC tags: As a result of preliminary experiment, IC tag could not be read when the interval was too narrow. Second experiment has the space in the interval of IC tags.

(3)Material and size of IC tags: Material and antenna size of IC tag is variety. Third experiment was performed by using ceramics type of IC tags which has high durability, general card type and paper type.

\subsection{Experiment Result}

It was confirmed that IC tags be influenced by the differences the interval of setting and the material on the reading rate. Figure 9 (a) and (b) shows the results of each research as mentioned above.

As a result, the reading rate of IC tags has decreased greatly by $30 \mathrm{~cm}$ or more on cement concrete. The reading rate at other places is higher than the concrete area (Figure 9 (a)). Additionally, the reading rate was rapidly decreased when the height is above $25 \mathrm{~cm}$ (Figure 9 (b)). Furthermore, the reader could not read UID in ceramics type of one when height is more than $20 \mathrm{~cm}$. The reading rate has decreased from $25 \mathrm{~cm}$ up in the height of the reader from all results.

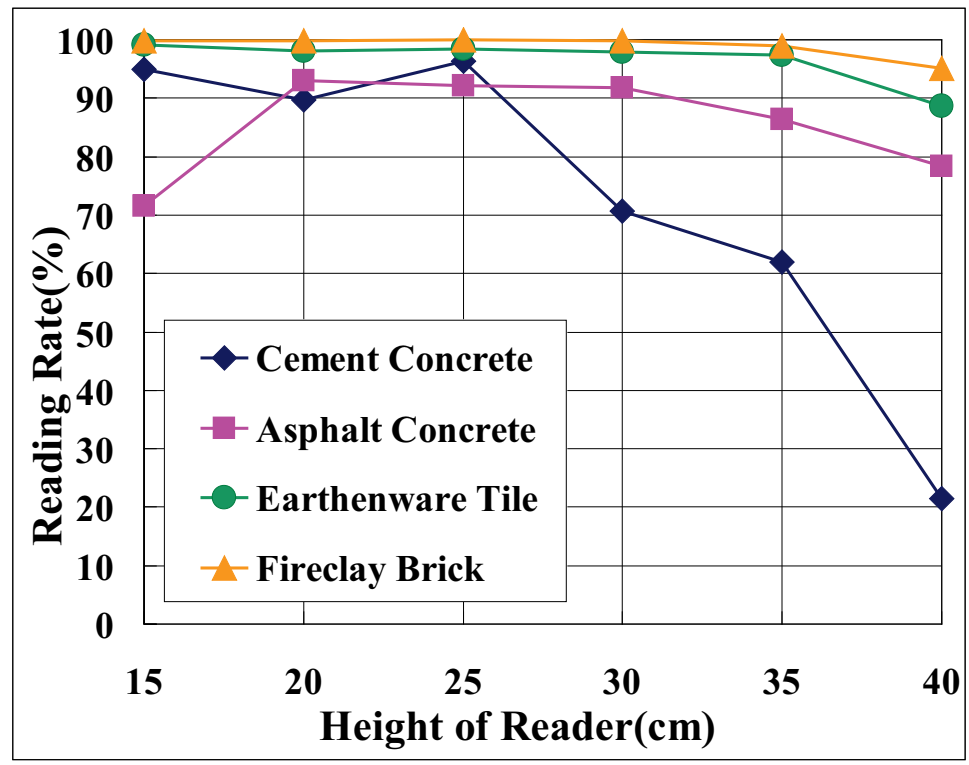

Fig. 9. (a) .Results of IC tag experiment (Reading rate by material of the ground) 


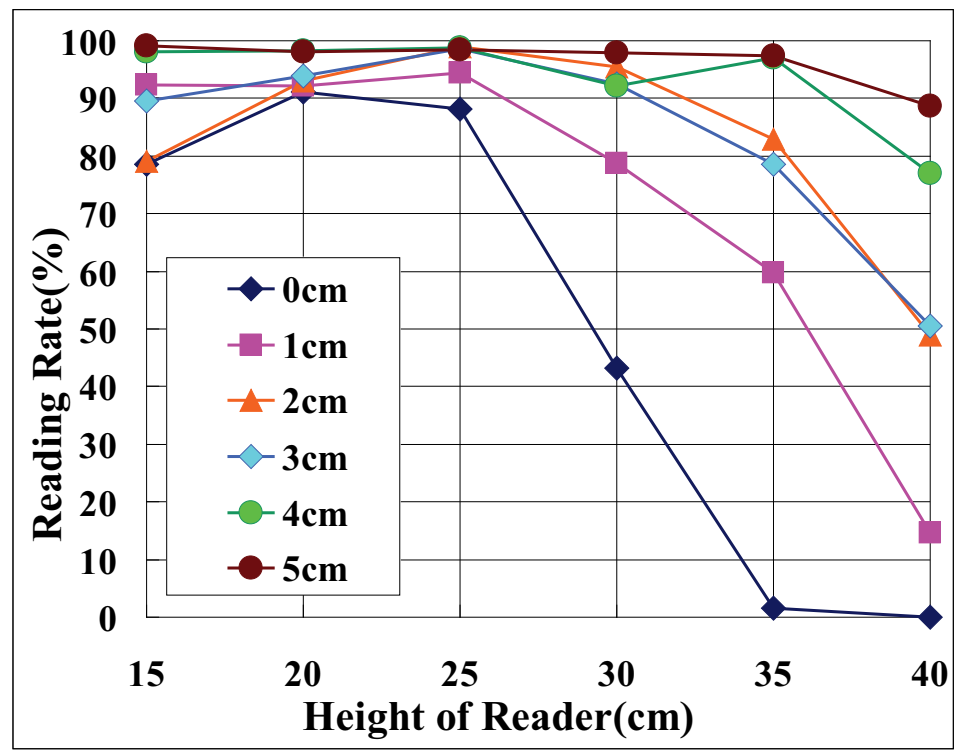

Fig. 9. (b) .Results of IC tag experiment (Reading rate by interval of IC tags)

\subsection{Consideration}

These results show that the decrease of reading rate was influenced by the moisture included in cement concrete. Installation interval of IC tags should leave space from about 5 $\mathrm{cm}$ to $10 \mathrm{~cm}$ to avoid anti-collision. Reading rate of ceramics type has narrow area because the ceramics type of IC tag uses alumina to increase durability and is thicker than other kinds of one. And IC tag which has small size of the antenna was low reading rate. Therefore, IC tag should be selected a large size as much as possible and the material should be considered of the environmental condition.

An appropriate reading distance was $20 \mathrm{~cm}$ depending on the material of IC tag. However, it is necessary to perform more detailed experiment under various conditions for the realization of proposed UM in my research.

\section{VERIFICATION EXPERIMENT OF IC TAG}

\subsection{Read Experiment by Shielding Material}

(1) Experimental Overview

It is necessary to clarify that the height of IC tag's reader and conditions of use. An experiment was performed where the IC tag was buried under the shielding material and was read when reader move through the material. The experiment was conducted by a hand truck to which the IC tags reader was attached. The UID of the IC tag was recognized and the reading rate was investigated. The reading rate was expressed for 1,000 IC tags. Figure 10 . shows read experiment by shielding material on wood. 


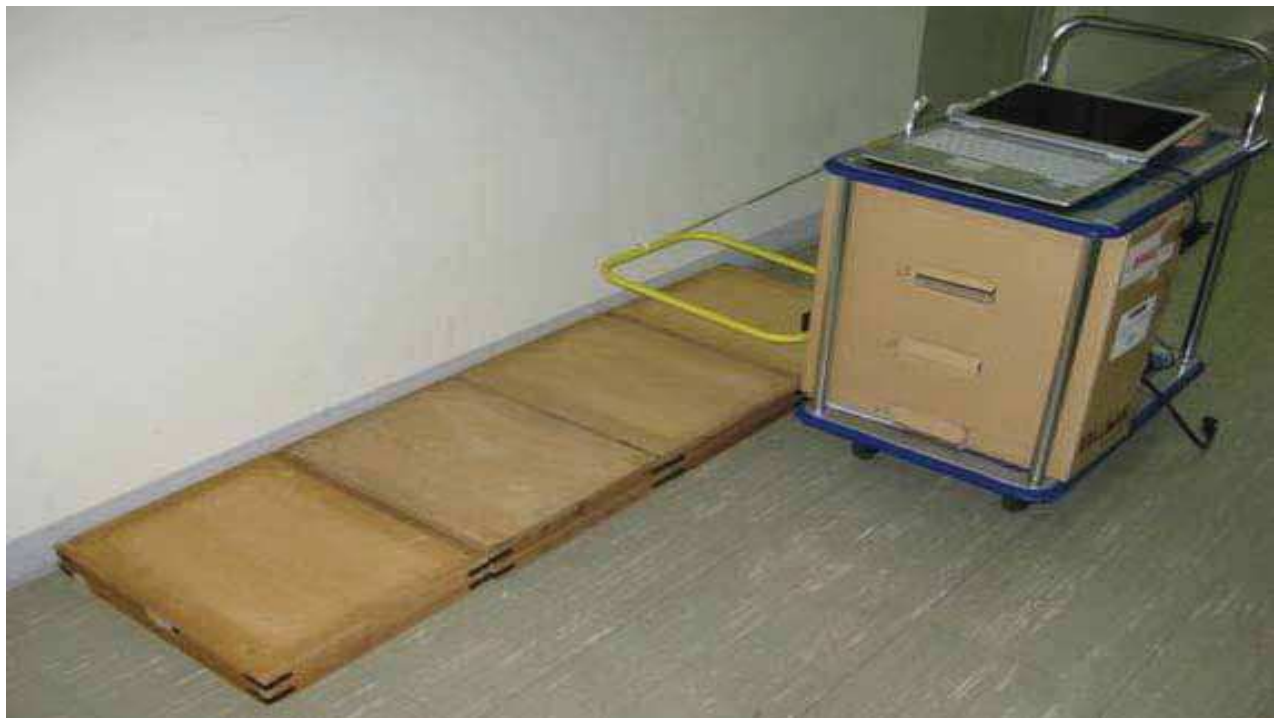

Fig. 10. Read experiment by shielding material (wood)

(2) Equipment in Use

Made by Welcat Inc.

IC tag's reader: EFG-400-01

An antenna of exclusive IC tag's reader writer: ANU-100-01

IC tag: card type(ISO15693, 13.56MHz)

(3) Setting conditions

(a) Used shielding material and its thickness

Wood: $3,6,9 \mathrm{~cm}$

Concrete: $6,12 \mathrm{~cm}$

Soil: $5,10,15 \mathrm{~cm}$

Shielding materials made of wood, concrete, and soil were used. These materials are used for general buildings and roads. The thickness of the shielding material has not been unified acquisition conditions

(b)The height of reader

The height of IC tag's reader was set to $15,20,25$, and $30 \mathrm{~cm}$. The reason was shown by $\mathrm{Mr}$. Shimano Co. Author who graduated from Kanazawa Institute of Technology (K.I.T.) where the reading rate was high when the height of the reader ranged form $15 \mathrm{~cm}$ to $30 \mathrm{~cm}$ in his research. In this experiment, the height was set to a maximum of $30 \mathrm{~cm}$ and a minimum of $15 \mathrm{~cm}$ according to the result.

(c) Setting intervals

A setting interval of the IC tag is $10 \mathrm{~cm}$ because it was the best interval by his research.

(d)The kinds of IC tags used

In the experiment, passive type was used. 


\subsection{Result and Considerations}

As the thickness of shielding materials is increased, the reading rates tend to decrease. However, each material shows a high reading rate. Therefore, this height is the best suited.

The following shows appropriate conditions obtained by the experiment.

(a) Interval of passive type: Over $10 \mathrm{~cm}$

(b) Size of passive type used: Large size

(c) Moving speed to read: Normal walking speed

(d) Height of reader: below $15 \mathrm{~cm}$

(e) Thickness of shielding materials: below $10 \mathrm{~cm}$

\subsection{Indoor Positioning Experiment}

An experiment was used the IC tag of active type. An advance of this type is to transmit radio waves at regular intervals automatically, detect and specify IDs existing in a wide maximum range of $20 \mathrm{~m}$. And it can control information as a person, an object, a position, time, and condition at real time. An experiment was investigated to discuss a method for setting active tag in a room and how to set in environment. By changing material and the height, a change in the member of need times and RSSI was verified. RSSI means a sensitivity to receive tag.

(1) Equipment in use

Made by Kyusyu Ten Co.

Wireless reader: TGS-R300W

Wireless tag: YGS-T300

Wireless router: WIN-G54/R4-M(Made by I O DATA Co.)

(2) Setting conditions

(a)The height of reader: $240 \mathrm{~cm}$

The height of reader is shown from the floor to the ceiling in experimentation area. It easy to receive the electric wave from a tag by reader is attached to the ceiling.

(b) The distance from a tag to a reader: $10 \mathrm{~m}$

(c) The time to read tag: 60 seconds

(d) Interval time of electric wave automatic transmission: 3 seconds

(e)Attached the material: person, wood and iron

According to statistics, an average height of Japanese is $170 \mathrm{~cm}$ for the past 5 years. So the height of the tag is set $170 \mathrm{~cm}$ at the maximum.

(3) Experimental Overview

An experiment was performed where a wireless tag is attached to wood, iron, and people. By changing material and the height, a change in the member of need times and RSSI was verified. The active tag can automatically received control position information from attached object. Therefore, it was assumed that a tag was attached to a human body in a basis pattern. Wood and iron were used in comparison with a person from the result of experiment. 


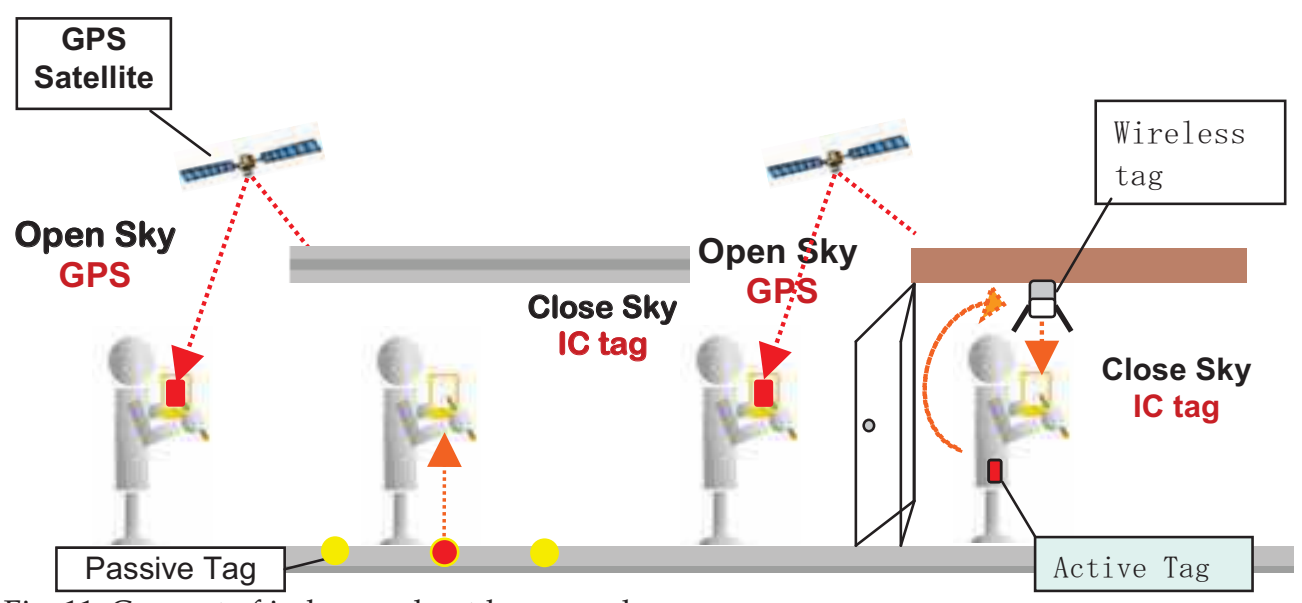

Fig. 11. Concept of indoor and outdoor seamless survey
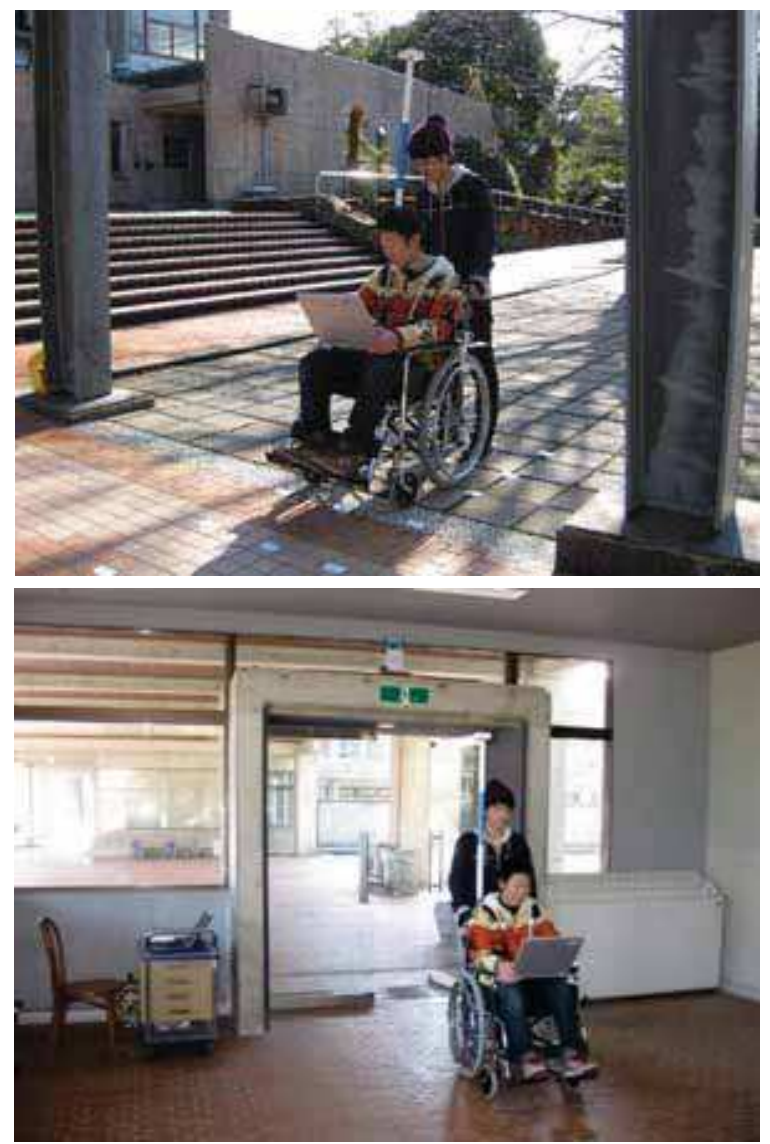

Fig. 12. Outdoor and indoor experiments 


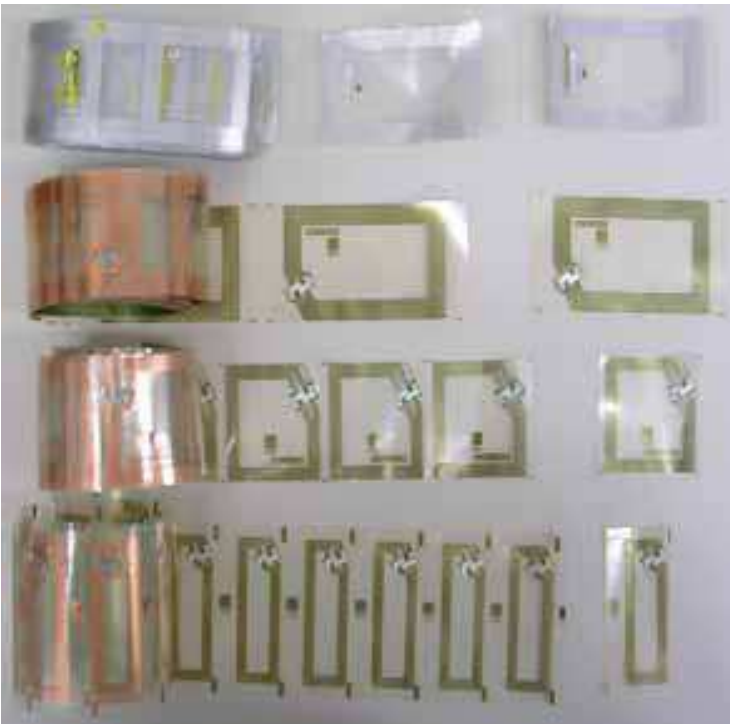

Fig. 13. IC Tags of Passive type

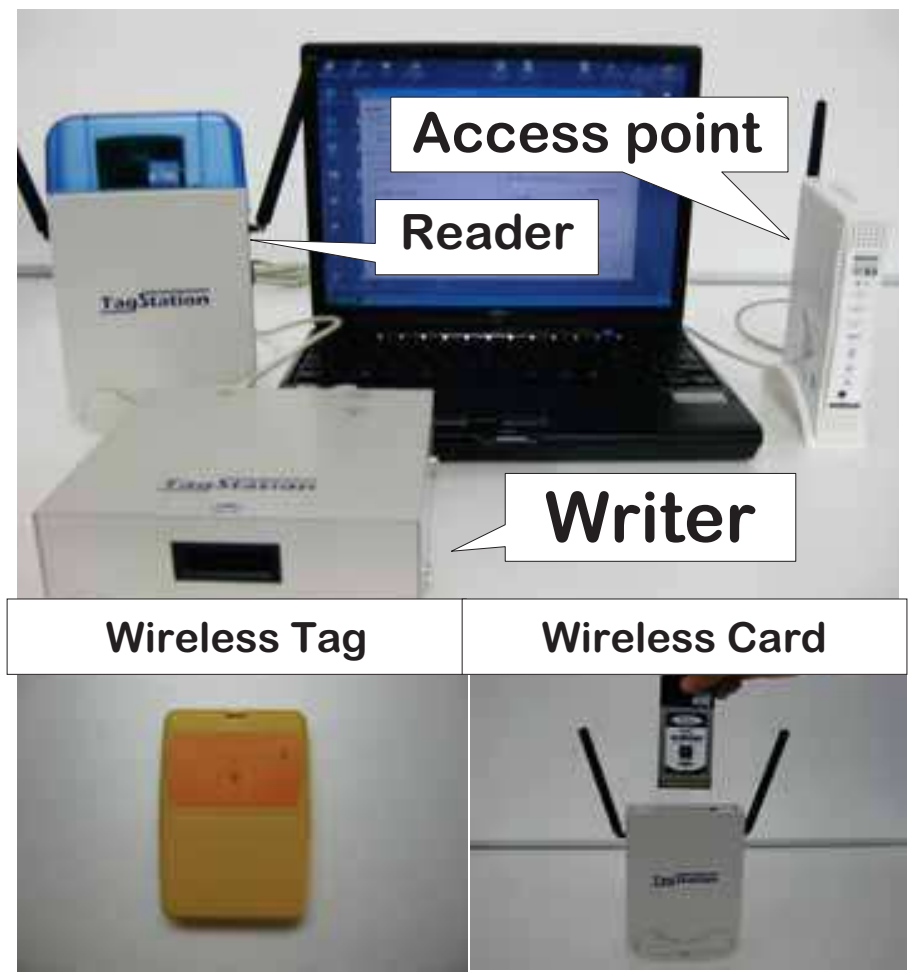

Fig. 14. IC Tag System of Active type 


\subsection{Results and Considerations}

Table 3 shows RSSI and read times. The times and RSSI show higher values when the tag is attached to the iron as compared with a person. It seemed that tag served as an antenna when it was attached to the iron, and electric wave to reader were amplified. In addition, each values of attaching to wood and person were similar to basis. Therefore, the tag does not affect reception sensitivity if it is attached to the wood or person.

\begin{tabular}{|l|c|c|c|c|c|c|c|c|}
\hline & \multicolumn{2}{|c|}{ Ocm } & \multicolumn{2}{c|}{$70 \mathrm{~cm}$} & \multicolumn{2}{c|}{$100 \mathrm{~cm}$} & \multicolumn{2}{c|}{$170 \mathrm{~cm}$} \\
\cline { 2 - 9 } & RSSI & times & RSSI & times & RSSI & times & RSSI & times \\
\hline Basis & 4 & 17 & 6 & 21 & 4 & 21 & 6 & 21 \\
\hline Wood & 4 & 18 & 6 & 19 & 5 & 19 & 4 & 21 \\
\hline Iron & 8 & 21 & 8 & 22 & 8 & 22 & 8 & 22 \\
\hline Person & 4 & 17 & 5 & 21 & 4 & 19 & 5 & 19 \\
\hline
\end{tabular}

Table 3. RSSI and times to read tag

\section{Update base map by using regional parameter}

"The map should be fresh" is a concept of our laboratory mentioned above. The purpose of study is to establish a method for updating a large-scale digital map for local government using a Real-Time GIS. The Real-Time GIS which was defined by our laboratory can be used to renew the new BM. The Real-Time GIS is a technique that updates the new BM instantly by the Real-Time Kinematic Global Positioning System (RTK-GPS), GIS, and mobile phones. These techniques have been called "Geoinfomatics" that is a new field of survey.

Japan has adopted a new general standard for map geometry since April 1, 2002. Ellipsoid of a new geodetic system in Japan is almost equal to WGS-84 of GPS. However, most of the digital maps of local government are still Tokyo Datum of an old geodetic system. To cope with two kinds of data which have different geodetic systems, it is necessary to transform coordinates.

In the master's thesis of Ms. Aki Okuno who graduated from Kanazawa Institute of Technology (KIT), she tried to solve the problem between the old and new geodetic systems by TKY2JGD and Affine Transformation. The result is listed below (Okuno, 2006).

1. The control point of transformation has to be located at four corners in the map. The exact point (national control point and public control point) of the control point could not be found in the field of survey.

2. A $1 / 500$ scale area is desirably converted. 
However, the method of making control points was not adopted because it is difficult to obtain the coordinates on a map and to find the points at the field. Therefore, the control points of town planning group data and cadastral data were used for coordinate transformation. Many control points are in a narrow area.

As a result, the transformed old map will be allowed to overlap to a new map measured by RTK-GPS.

\section{Control Point for Transformation}

To transform the old BM, the control point was used at the field. In the research, the control point means a point for showing both exact coordinates of Tokyo Datum and JGD2000. A verification area has accurate data of Tokyo Datum (based on BESSEL ellipsoid and rectangular plane coordinate system), and the data are managed by the Town Planning Group and the Cadastral Section in Kanazawa City. Experiment areas are "Area A," "Area B," "Area C," and "Area D," (they are marked as A, B, C and D in Figure 17 at next page). Figure 15 shows Sample of verification are (Area D).

To obtain the coordinates of JGD2000, this study used static positioning of GPS and Virtual Reference Station-GPS (VRS-GPS) at test fields (Figure 15). A and B were measured over 2 hours using static positioning of GPS. C and D were measured for one minute using VRS-GPS. The measurement time is decided by the law of Japan.

The control points of the Town Planning Group data and Cadastral Section data were installed simply. Especially, the control point number could be discerned on a road. Therefore, everyone can easily confirm the control point at the field. However, in the future, marking ink of the control point number will disappear. A better method for maintaining and managing the control point for coordinate transformation is to adopt the control point of town blocks and an IC tag.

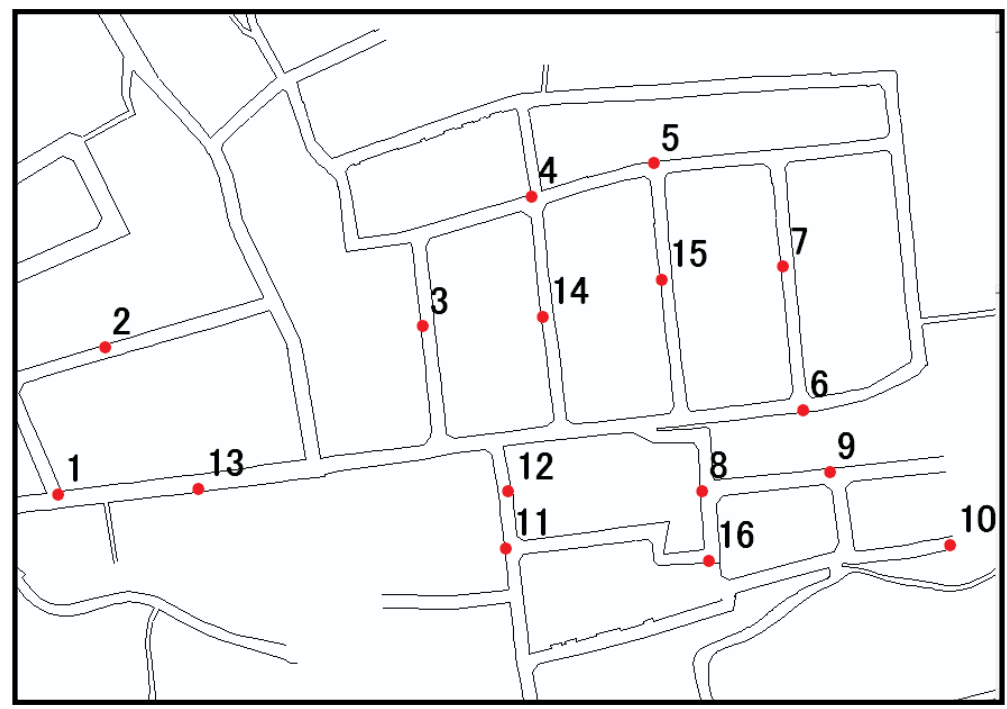

Fig. 15. Sample of verification area (Area D) 


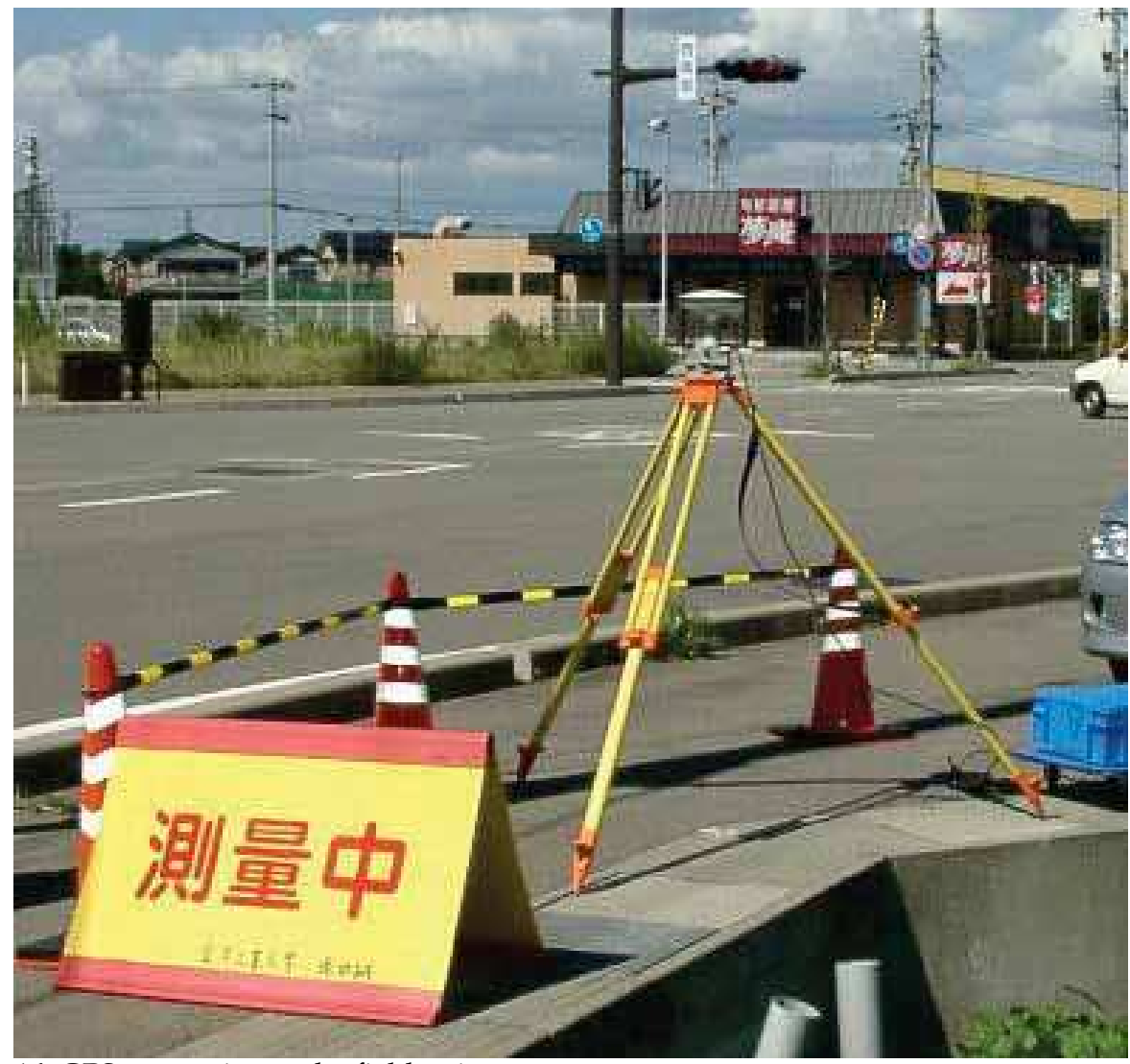

Fig. 16. GPS measuring at the field point

\section{Verification of TKY2JGD for Japanese Standard Conversion}

Geographical Survey Institute of Japan (GSI) opened a website for conversion parameters and programs (TKY2JGD). First, the coordinates of Tokyo Datum of the old geodetic system were transformed to new ones by TKY2JGD. The differences between calculation results and GPS measurement data were verified. The detail results are not shown in this paper by page limitation. The average differences at A, B, C, and D were about 11.3, 31. 9, 11, and $14 \mathrm{~cm}$ respectively. In addition, $\mathrm{A}, \mathrm{B}, \mathrm{C}$ and $\mathrm{D}$ were rotary, parallel, south-east, and south-southeast respectively.

The areas A, B, C and D have a regular accident error. Converted data almost all corresponded to digital BM data in a small-scale map. However, the parameter could not be adopted in a large-scale map. Because the parameter area of TKY2JGD is too large, it is necessary to make the parameter in a narrow area. 


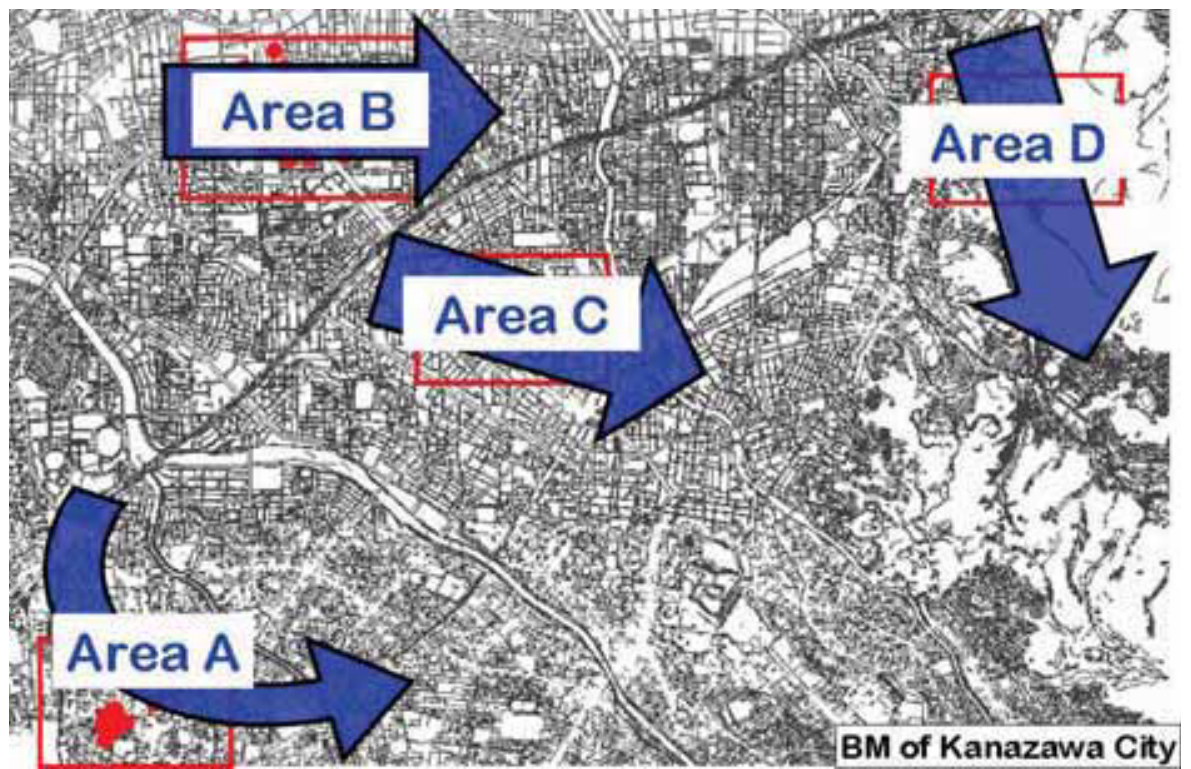

Fig. 17. Differences of vector in each test fields

\section{Verification of High-Accuracy regional Parameter Using Affin Transformation in Narrow Area}

On the verification, Affine Transformation is the most general and simple method in various geometric conversions. Affine Transformation makes the three parameters. Elements were rotation, scale and parallel. These parameters transform the geodetic system $(x, y)$ of old geodetic system to $\left(x^{\prime}, y^{\prime}\right)$ of new one. The conversion formula is as follows.

$$
\begin{aligned}
& x^{\prime}=x_{0}+k_{x} x-\theta_{y} y \\
& y^{\prime}=y_{0}+\theta_{x} x+k_{y} y
\end{aligned}
$$

Where $\quad(x, y)=$ coordinates of Tokyo Datum

$\left(x^{\prime}, y^{\prime}\right)=$ coordinates of JGD2000

$\left(\mathrm{x}_{0}, \mathrm{y}_{0}\right)=$ parallel transformation

$\mathrm{k}=$ scale

$\mathrm{k}_{\mathrm{x}}=$ scale of $\mathrm{X}$ axis

$\mathrm{k}_{\mathrm{y}}=$ scale of $\mathrm{Y}$ axis

$\theta=$ rotation

$\theta_{\mathrm{x}}=$ rotation of $\mathrm{X}$ axis

$\theta_{\mathrm{y}}=$ rotation of $\mathrm{Y}$ axis

Parameters obtained by Affine Transformation are called "High-Accuracy Regional Parameter (HARP)". HARP was calculated by the coordinates of Tokyo Datum and GPS data. In the master's thesis of Ms. Aki Okuno, she performed calculation by 11 methods having a different number of control points and different places of control points, and 
standard deviation of Affine Transformation had only $3 \mathrm{~cm}$ errors when using control points at four corners. In this paper, four control points were located at four corners of the area. In addition, calculated parameters by the coordinates of $\mathrm{A} B, \mathrm{C}$ and $\mathrm{D}$ were named parameter $\mathrm{A}$, parameter $\mathrm{B}$, parameter $\mathrm{C}$, and parameter $\mathrm{D}$ respectively.

Transformation methods are as follows.

Areas A, B, C, D were transformed by using parameter A, B, C, D.

Areas $\mathrm{B}, \mathrm{C}, \mathrm{D}$ were transformed by using parameter $\mathrm{B}$.

\begin{tabular}{|c|c|c|}
\hline \multirow{2}{*}{ Experiment Area } & \multicolumn{2}{|c|}{ Error(m) } \\
\cline { 2 - 3 } & $\sigma x$ & $\sigma y$ \\
\hline \hline Area A (parameter A) & 0.002 & 0.003 \\
\hline Area B (parameter B) & 0.001 & 0.002 \\
\hline Area C (parameter C) & 0.001 & 0.001 \\
\hline Area D (parameter D) & 0.005 & 0.003 \\
\hline
\end{tabular}

Table 4. Error calculated by the same parameter

\begin{tabular}{|c|c|c|}
\hline \multirow{2}{*}{ Experiment Area } & \multicolumn{2}{|c|}{ Error(m) } \\
\cline { 2 - 3 } & ox & oy \\
\hline \hline Area B (parameter B) & 0.026 & 0.010 \\
\hline Area C (parameter B) & 0.008 & 0.050 \\
\hline Area D (parameter B) & 0.111 & 0.029 \\
\hline
\end{tabular}

Table 5. Error calculated by different parameter

Table 4 shows that result of adapting the parameter of the same area. As a result of verification, the error was not more than $1 \mathrm{~cm}$ in $X$ and $Y$.

Table 5 shows that result of adapting the parameter of a different area. The error was large in areas D. However, the error of area $A$ and area $C$ are not more than $3 \mathrm{~cm}$ in $X$ and $Y$. There is a possibility that the large area can be converted by one parameter. In addition, the overlaying of New BM and transformed Map should be verified. Then, the accuracy of coordinate transformation will become clear.

\section{Characteristics of Error Margin in Large Area Using Triangulation Point}

\subsection{Triangular point for coordinate transformation}

The character of the error was clarified from the result of experiment. However, the regularity of the error in the large area was not able to be clarified. Therefore, the regularity of the error was comprehended by using a triangulation point in large area. Triangulation 
point is managed by GSI and, the point is set up in large area. This experiment used triangular points of 53 places in the Kanazawa city.

\subsection{Conversion result of triangulation point}

On the result of the coordinate transformation, the regularity in the large area indicated the direction of the southeast (Figure 18). In addition, the research area was verified separately plain field and along the mountain. As a result, the character of plain field indicated the southeast pattern, and mountain indicated the south-southeast pattern. Characteristic of triangulation point was compared with to area of verification. As a result, feature of error was similar in the various areas (Figure 19). Therefore, the error in the verification area has the possibility that a triangulation point influences, and the error of a triangular point has the possibility that diastrophism influenced.

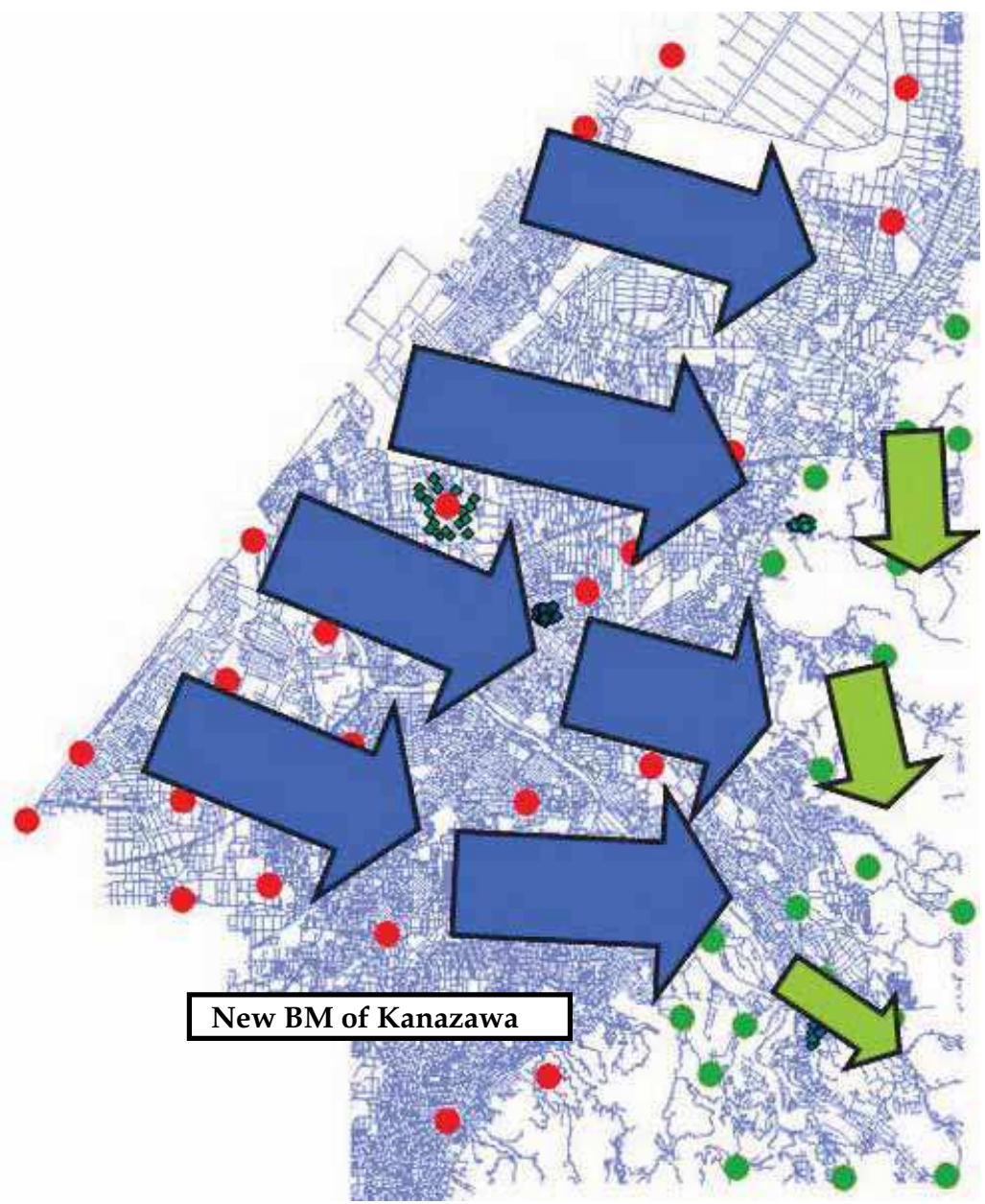

Fig. 18. Character of error in large area (Kanazawa City) 


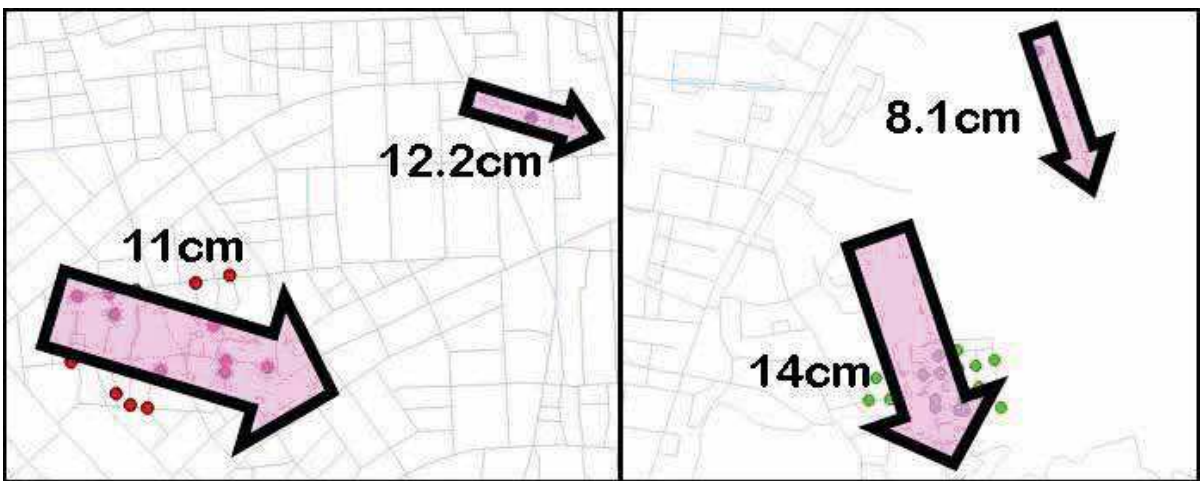

Fig. 19. Comparison between triangulation point and verification area

\section{Overly of Transformed Map and New BM of Kanazawa City}

Large scale Base Maps used in local government was transformed by using the parameter. Parameter was calculated in Chapter 10 and transformed Base Map was overlapped with New BM. An original program for transformation was made by our laboratory. Transformation parameters were inputted to the program and dot-line from Figure 20((a)-(e)) shows transformed Map using same area parameter. Heavy line in Figure $20((\mathrm{a})-(\mathrm{e}))$ shows the transformed Map by using parameter of Area A, and narrow line is road data of New BM in the city of Kanazawa's new base map (Kiban Chizu)

Result of applying same area parameter to same area, the error margin of area A, B, C, and $\mathrm{D}$ were about $10 \mathrm{~cm}, 4.53 \mathrm{~m}, 12.64 \mathrm{~m}$, and $5.36 \mathrm{~m}$ respectively. On the result of overlapping New BM and converted map with area of A, those maps were accurately overlapped (Figure 20(a)),however, New BM and the converted map of area B, C and D were not overlapped (Figure 20(b),(c),(d)). Result of applying parameter B, the error margin of area A, C, and D were about $6.58 \mathrm{~m}, 4.66 \mathrm{~m}$, and $4.69 \mathrm{~m}$ respectively (Figure 20 (a), (c) and (d)). Therefore, all area did not overlap. Applying the parameter of another area to the area was very difficult.

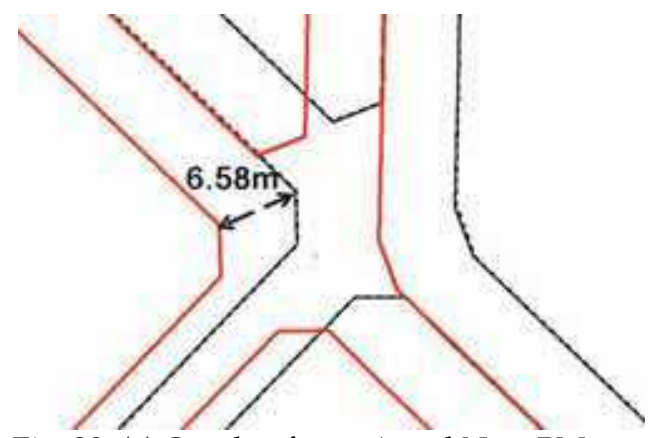

Fig. 20. (a) Overly of area A and New BM

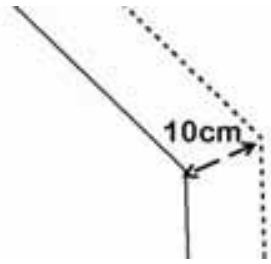

(b) Overly of area A and New BM (Amplifier) 
Fig. 20. (c) Overly of area B and New BM
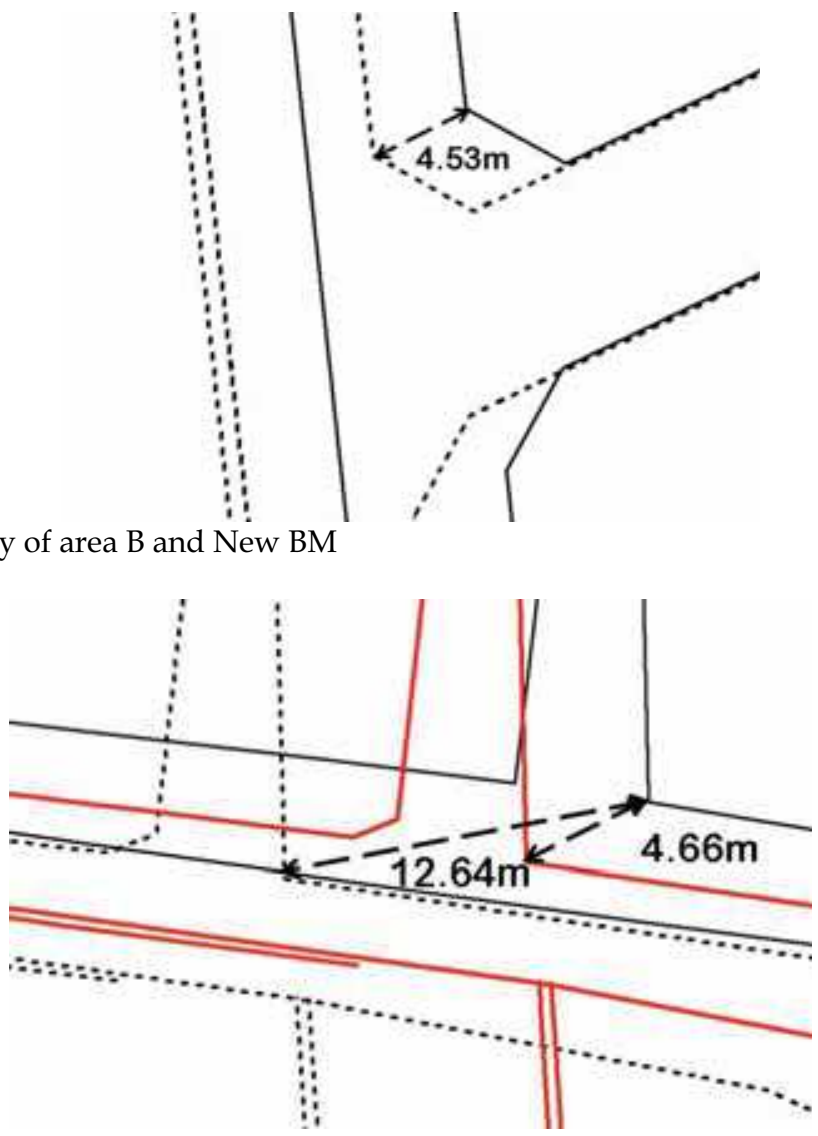

Fig. 20. (d) Overly of area C and New BM

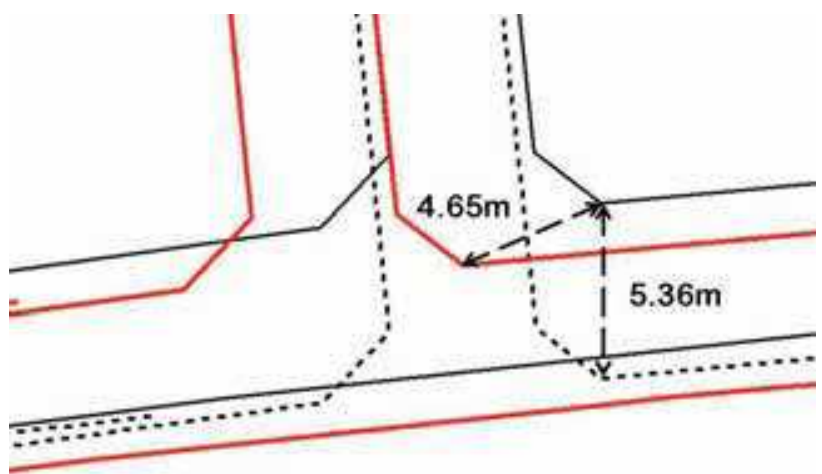

Fig. 20. (e) Overly of area D and New BM 


\section{Overly of GPS Data and New BM}

New BM was overlapped with GPS data acquired by VRS-GPS.Actual experiment was performed by using RTK-GPS of Virtual Reference Station (VRS-GPS). VRS-GPS does not need to set the reference station. Virtual reference station was made virtually around the measuring point. Distance of virtual point to actual point is about $3 \mathrm{~m}$ to $5 \mathrm{~m}$. Revision information of rover station was sent to mobile phone by using wireless system. This system is possible to measure by only one person with light baggage (Figure 21).

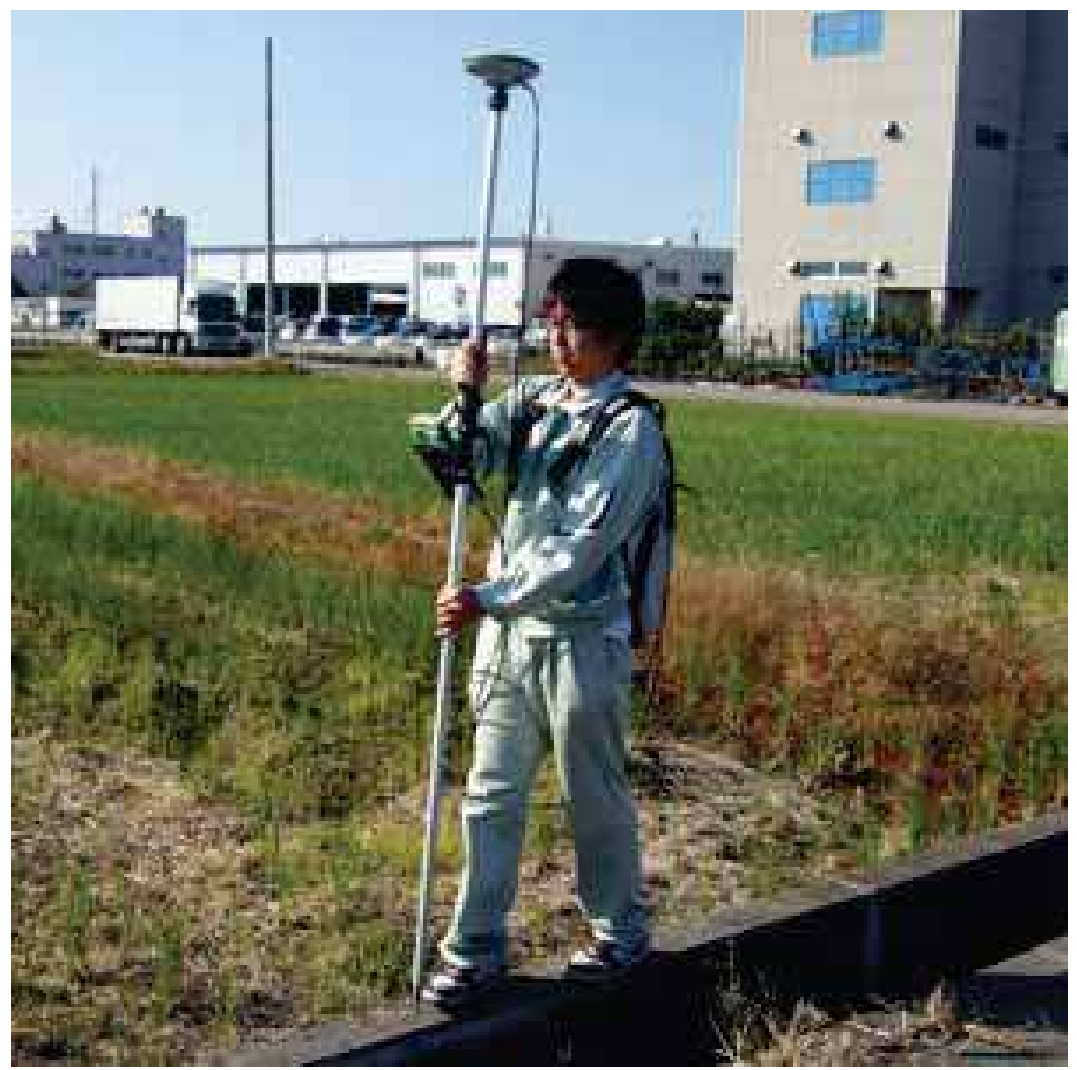

Fig. 21. VRS-GPS on the road line

A circle symbol and solid line in Figure 22((a)-(f)) means VRS-GPS and road line of New BM in the Kanazawa city respectively. Actual experiment was performed at district in A, B and D. GPS was not able to be observed, because area $C$ was a residential area.

Difference between GPS data and New BM were $22 \mathrm{~cm}$ in Area A, $32 \mathrm{~cm}$ in Area B and $28 \mathrm{~cm}$ in Area D (Figure 22). The GPS data was partially overlapped to the map, therefore the update of the New BM using VRS-GPS is effective at that area. However, a part of GPS data and the map did not overlap because GPS is influenced easily by the measurement environment. It is the reason why the update region is limited. 


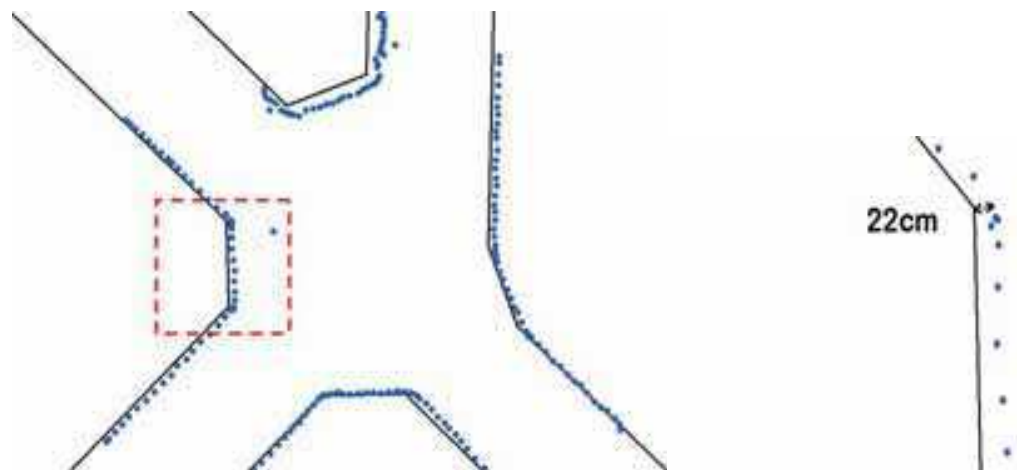

Fig. 22. (a) Overly of VRS-GPS and Area A (b) Overly of VRS-GPS and Area A (Amplifier)

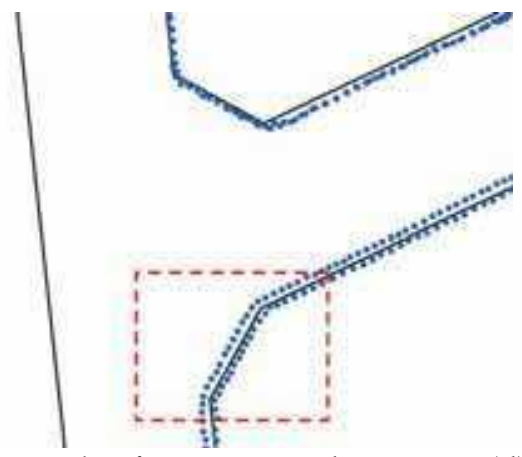

(d) Overly of VRS-GPS and Area B (Amplifier)

Fig. 22. (c) Overly of VRS-GPS and Area B
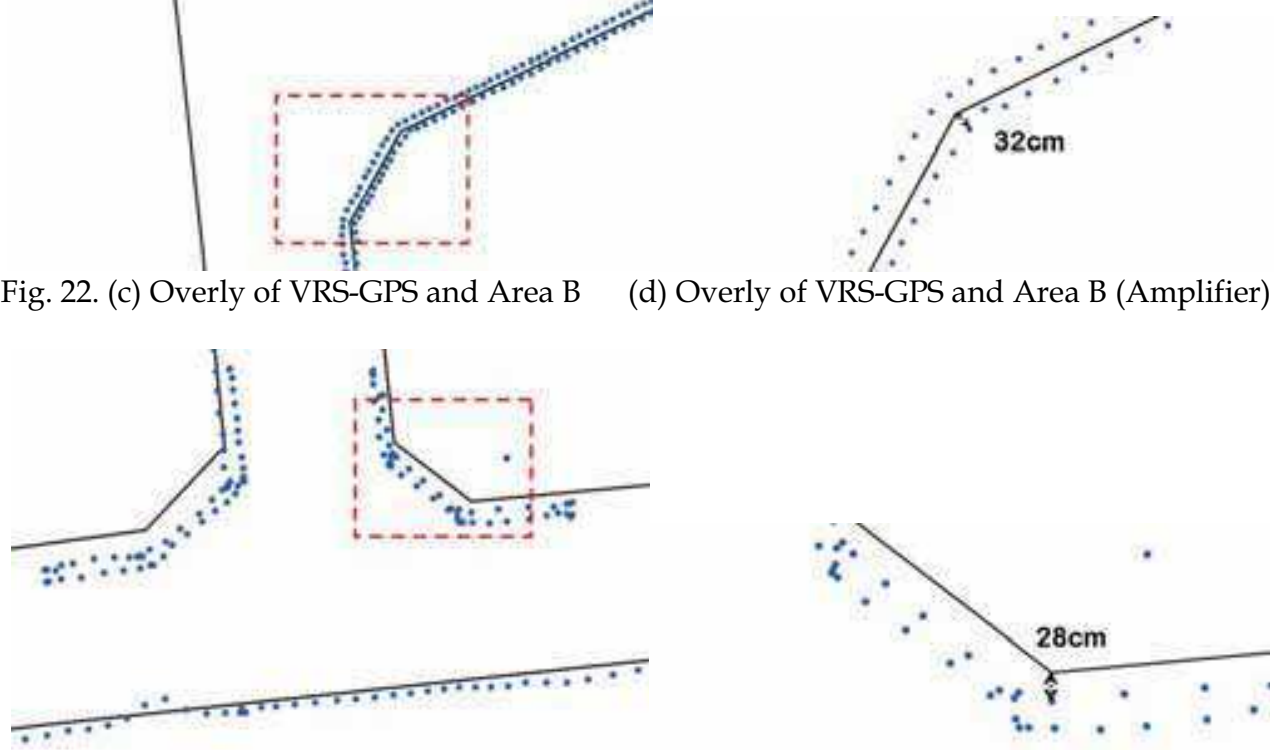

Fig. 22. (e) Overly of VRS-GPS and Area D

(f) Overly of VRS-GPS and Area D (Amplifier)

\section{Conclusion}

The experiment was conducted by using a D-GPS and a VRS-GPS attached to wheelchairs. As a result, the positioning data with high-accuracy was obtained under the open sky. However, there were measurement errors including cycle slip and multipath at some places under closed sky. It showed that it is very difficult to solve these problems by using a GPS only. In addition, safe UM cannot be made only by the current technology. Therefore, the 
study proposed the method by using geoinformatics and IC tags. Next step is to perform a spatial simulation and it is expected that the proposed method will establish useful UM in the near future.

If the government adopt high-resolution satellite imageries as a background of new BM, the government and general users can easily recognize the urban conditions. We recommend that the government introduce the system of "REAL TIME GIS" and Remote Sensing imageries for their work. The simplification of the mapping process, reduction of mapping and updating costs, and understanding of accurate urban conditions are connected with the improvement of improved service to the citizens. In the experiment, the coordinate transformation of the large-scale map for local government was successfully conducted at a part of test field. However, old maps were not accurately transformed to the new geodetic system. Therefore, it is necessary to investigate the method of the highly accurate conversion.

It is suggested that the town block control point is very useful tool to transform the map. The town block control point was made by GSI on" Basic Survey of Town Block for Renewal of Urban Areas." The town block control points has accurate data because they are managed by the nation, and they were set up at a short interval (every $200 \mathrm{~m}$ ).

Therefore, accurate reference point data can be acquired. If the town block control point is used for geometrical transform, the characteristic of the difference between the old geodetic system and the new one understand easily, and coordinate transformation will perform more efficiently. VRS-GPS and New BM was overlapped. As a result, the effectiveness of VRS-GIS was confirmed. Collaboration of Remote Sensing, Real Time GIS will help local government renew a large-scale map and new BM, and this research will contribute to update of new BM.

Finally, I would like to recommend strongly that local governments have to establish the conference to revise large scale map by using NSDI which include country, prefecture, and cities. It is most important point that reduces much labor money and time.

Previous research confirmed whether high-accuracy positioning information continuously by a D-GPS and VRS-GPS. However, GPS can be obtained positioning was not performed in closed sky. It was proposed to obtain positioning information by a high-accuracy GPS positioning technology like an IC tag utilized at intelligent for control points. Kind of IC tag has passive type and active type. The method is different by a purpose of use. In this study, it became clear how to use appropriately passive type IC tags. Active type IC tags are in a stage of growth on territory of geoinfomatics technology. In the future, simulation experiments will be conducted to verify whether positioning information obtained by GPS and IC tags can be shown on the GIS.

\section{Acknowledgement}

The authors wish to special thank to Program Director Ms.Naoko Matsuda of Nonoichi Foundation for Information and Cultural Promotion, and Ms.Aki Okuno of KOKUSAI KOUGYO Co., LTD. Survey, KokudoKaihatu Center, Ltd., and Nihonkai consultant, Ltd, that offered data. Moreover, we would liketo thank to Nonoichi town office and the cooperation of Mr. Uchida and Mr. Fujita, Leica Geosystems Co., Ltd. which offered much data and suggestions of analysis. Moreover, I would like to express our heartfelt gratitude to 
the cooperation of Mr. Fukumori, Toppan Printing Co., Ltd. for supplying IC tag's information and samples.

\section{References}

Alfred L,(2004),GPS Satellite Surveing, Third Edition,ISBN0-471-05930-7, John Wiley \&Sons Ltd.

Arai C. et al.(2001) Research on Real-Time Revision of Base Map using Remote Sensing and RTK-GPS, IGARSS2001,IEEE International Geoscience and Remote Sensing Symposium, 0-7803-7033-3/1,1-3.

Arai C. et al.(2002) Management of Mapping in Local Government using Remote Sensing and the REAL TIME GIS, IEEE International Geoscience and Remote Sensing Symposium 2002, 0-7803-7537-8/02,1-3.

Arai C. et al.(2003) An Application of Remote Sensing and REAL TIME GIS to Digital Map for Local Government, IEEE 2003 International Geoscience and Remote Sensing Symposium, 0-7803-7930-6/3,1-3.

Christian H,Peter A.W \& Markus G.(2008).Updating geospatial database from images, Advanced in Photogrammetry,Remote Sensing and Spatial Information Science 2008 ISPRS Congress Book,Li,Chen \& Baltasavias(eds),pp.355-362,CRC Press/Balkema,ISBN 978-0-415-47805-2, John Wiley \&Sons Ltd.

Helmut M,Stefan H \& Uwe S,(2008). Automated extraction of road,buildings and vegetation from multi-source data, Advanced in Photogrammetry,Remote Sensing and Spatial Information Science,2008 ISPRS Congress Book,Li,Chen \& Baltasavias(eds), pp.213-226,CRC Press/Balkema,ISBN 978-0-415-47805-2, John Wiley \&Sons Ltd.

Haigans S,Qiming Z,Jianya G \& Guorui M,(2008).Processing of multitemporal data and change detection, Advanced in Photogrammetry,Remote Sensing and Spatial Information Science 2008 ISPRS Congress Book,Li,Chen \& Baltasavias(eds),pp.227-247,CRC Press/Balkema,ISBN 978-0-415-47805-2, John Wiley \&Sons Ltd.

Journal of JACIC (Japan Construction Information Center) Information, (2007). Feature of Spatial Information Society in theNational Spatial Data Infrastructure of Japan (NSDI), Geographical Survey Institute of Japan (GSI), http:/ /law.e-gov.go.jp/htmldata/H19/H19HO063.html (accessed 6 Dec. 2007)

JACIC (Japan Construction Information Center), (2005).Journal of JACIC Information, Feature of IC tag, Vol.20, No.1

Moriya M, Shimano S, Shikada M (2007). Map renewal technique by using collaboration of GPS, GIS and Remote Sensing, GPS and Remote Sensing, IEEE 2006 International Geoscience and Remote Sensing Symposium、p255, 1-3

Michael N.D,(2005),Foundamentals of Geographic Information System,Third Edition,ISBN 0-471-45149-5, John Wiley \&Sons Ltd

Matsuda N et al.(2002) Proposal of Renewal System for Barrier-free Map by using Remote Sensing and RTK-GPS, IEEE International Geoscience and Remote Sensing Symposium 2002, 0-7803-7537-8/02,1-3.

Matsuda N et al.(2003) Actual experiment of renewal system for barrier-free map by using Remote Sensing and RTK-GPS, IEEE 2003 International Geoscience and Remote Sensing Symposium, 0-7803-7930-6/3,1-3,2003. 
Matsuda N. (2003). Application of Real Time GIS using Remote Sensing and RTK-GPS for Local Government, Resume of Master's thesis Open Hearing Conference at KIT

Okuno A. (2004) Application of REAL TIME GIS using Remote Sensing and RTK-GPS for Local Government, IEEE 2004 International Geoscience and Remote Sensing Symposium, 0-7803-874,1-3.

Okuno A. (2006).Coordinate Transformation of Large Scale Map and Establishment of Real Time GIS, Resume of Master's thesis Open Hearing Conference at KIT,

Paul A.Longlay et al. (2005), Geographic Information System and Science, 2nd edition, pp.385-403, ISBN 0-470-87000-1, John Wiley \&Sons Ltd

Shikada M, et al.(2004).Coordinate Transformation of Large-scale Map Data for Real-time Update of Maps using RTK-GPS, The Journal of Survey,Vol.54,No.8,pp.10-13

Shikada M, et al. (2004).Coordinate Transformation of Large-scale Map Data for Real-time Update future, JACIC, Vol.22, No.3

Shiratori K. (2005). Change the Business by IC tag, Printed in Paru Printing Co., Ltd.

Shunlin L,Michael S \& Mathias K,(2008).Remote Sensing signatures:Measurements,modelling and applications, Advanced in Photogrammetry, Remote Sensing and Spatial Information Science ISPRS Congress Book,Li,Chen \& Baltasavias(eds), pp.127-143,CRC Press/Balkema, ISBN 978-0-415-47805-2, John Wiley \&Sons Ltd. 


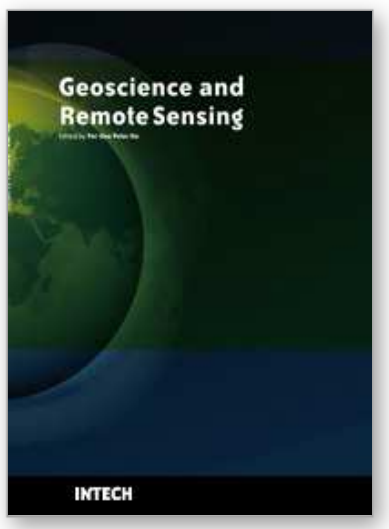

\author{
Geoscience and Remote Sensing
}

Edited by Pei-Gee Peter Ho

ISBN 978-953-307-003-2

Hard cover, 598 pages

Publisher InTech

Published online 01, October, 2009

Published in print edition October, 2009

Remote Sensing is collecting and interpreting information on targets without being in physical contact with the objects. Aircraft, satellites ...etc are the major platforms for remote sensing observations. Unlike electrical, magnetic and gravity surveys that measure force fields, remote sensing technology is commonly referred to methods that employ electromagnetic energy as radio waves, light and heat as the means of detecting and measuring target characteristics. Geoscience is a study of nature world from the core of the earth, to the depths of oceans and to the outer space. This branch of study can help mitigate volcanic eruptions, floods, landslides ... etc terrible human life disaster and help develop ground water, mineral ores, fossil fuels and construction materials. Also, it studies physical, chemical reactions to understand the distribution of the nature resources. Therefore, the geoscience encompass earth, atmospheric, oceanography, pedology, petrology, mineralogy, hydrology and geology. This book covers latest and futuristic developments in remote sensing novel theory and applications by numerous scholars, researchers and experts. It is organized into 26 excellent chapters which include optical and infrared modeling, microwave scattering propagation, forests and vegetation, soils, ocean temperature, geographic information, object classification, data mining, image processing, passive optical sensor, multispectral and hyperspectral sensing, lidar, radiometer instruments, calibration, active microwave and SAR processing. Last but not the least, this book presented chapters that highlight frontier works in remote sensing information processing. I am very pleased to have leaders in the field to prepare and contribute their most current research and development work. Although no attempt is made to cover every topic in remote sensing and geoscience, these entire 26 remote sensing technology chapters shall give readers a good insight. All topics listed are equal important and significant.

\title{
How to reference
}

In order to correctly reference this scholarly work, feel free to copy and paste the following:

Shikada Masaaki, Takeuchi Sayaka, Shimano Sota and Moriya Mitoshi (2009). Application of Real Time GIS, Remote Sensing and IC Tag for Realization of Geospatial Information Society, Geoscience and Remote Sensing, Pei-Gee Peter Ho (Ed.), ISBN: 978-953-307-003-2, InTech, Available from:

http://www.intechopen.com/books/geoscience-and-remote-sensing/application-of-real-time-gis-remotesensing-and-ic-tag-for-realization-of-geospatial-information-soc

\section{INTECH}

open science | open minds

\section{InTech Europe}

University Campus STeP Ri

\section{InTech China}

Unit 405, Office Block, Hotel Equatorial Shanghai 
Slavka Krautzeka 83/A

51000 Rijeka, Croatia

Phone: +385 (51) 770447

Fax: +385 (51) 686166

www.intechopen.com
No.65, Yan An Road (West), Shanghai, 200040, China 中国上海市延安西路65号上海国际贵都大饭店办公楼405单元 Phone: +86-21-62489820

Fax: +86-21-62489821 
(C) 2009 The Author(s). Licensee IntechOpen. This chapter is distributed under the terms of the Creative Commons Attribution-NonCommercial-ShareAlike-3.0 License, which permits use, distribution and reproduction for non-commercial purposes, provided the original is properly cited and derivative works building on this content are distributed under the same license. 